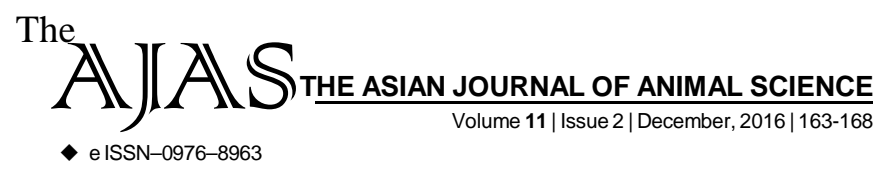

DOI : 10.15740/HAS/TAJAS/11.2/163-168 Visit us | www.researchjournal.co.in

\title{
Cytogenetical techniques for improvement of cattle
}

KAVITA P. PATIL AND S.G. GUBBAWAR

\section{Author for Corresponding -}

KAVITA P. PATIL

Mahatma Phule Krishi

Vidyapeeth, Rahuri,

AHMEDNAGAR (M.S.) INDIA

See end of the article for

Coopted authors'
KEY WORDS...... Cytogenetical techniques, Cattle

HOW TO CITE THIS ARTICLE - Patil, Kavita P. and Gubbawar, S.G. (2016). Cytogenetical techniques for improvement of cattle. Asian J. Animal Sci., 11(2): 163-168. DOI : 10.15740/HAS/TAJAS/11.2/163168.

ARTICLE CHRONICLE - Received : 15.10.2016; Accepted : 26.11.2016

\section{INTRODUCTION}

The animal genetic resources of India are represented by a broad spectrum of livestock. The genetic characterization of synthetic crossbred cattle is a major prerequisite in its conservation as well as improvement programmes. It helps in confirmation of the species of origin.

Cytogenetics is the correlated study of genetics and cytology. Relationship of specific genes with specific chromosomes is actually science of cytogenetics. It basically involves study of chromosome structure and behaviour. Animal cytogenetics is useful for enhancing reproductive performance, genetic capability, management and care in health, diseases of all classes of domestic animals.

The karyotype of a population of cells or an organism is the catalogue of the chromosomes of a typical or an average cell. Karyotyping is a useful technique in experimental biology. It can help in screening the breeding bulls for existence of hereditary diseases caused by detectable chromosome effects, significantly when such bulls are used in the artificial insemination programmes.

Chromosome identification has traditionally been dependent on their morphological characteristics such as relative lengths, arm ratios and presence or absence of secondary constrictions. However, the development of chromosome banding techniques during the last more than two decades provided a very useful additional tool for identification of individual chromosomes within the complement. The stains instead of uniformly dying the entire chromosome display characteristic bands. Individual chromosome can be observed for detection of abnormalities if any. Banding patterns also permit to establish a correlation between linkage maps and cytological maps. Modern cytogenetic studies find application in understanding heredity mechanisms, transmission of genetic diseases, cytotaxanomy and characterization of genetic resources.

\section{Theory of chromosome : \\ Chromosome:}

Darkly stained bodies of nucleus, capable of self reproduction and play vital role in heredity, mutation, variation and evolutionary development of the species.

\section{Chromosome number:}

Remains constant for particular species. E.g. cattle $(2 n=60)$. 